\title{
Fluctuations of Oil Prices and Gross Domestic Product in Indonesia
}

\section{Najihah Hussain}

Rutgers University, USA

\begin{abstract}
The main aim of the study was to find out the impact of fluctuations of oil prices on the economic progress measured using GDP of Indonesia. The research design was quantitative as the data collect is in numeric form. The data is collected from the secondary sources including World Bank and Fred St. Louis. A total of 10 years data was collected ranging from 2009 to 2018 based on monthly frequency. The analysis was conducted using ADF testing for stationarity, descriptive statistics and Autoregressive Distributed Lag (ARDL) model is conducted in order to find the impact of fluctuations of oil prices on the Indonesian economic progress. It was found from the preliminary assessment that data of GDP index had unit root, therefore, ARDL model was opted. It was found that oil price volatility affected the economic progress of Indonesia positively in the short-run. It was also evaluated that GDP is significantly dependent on its lagged values. The research underpinned the case of Indonesia therefore this research is limited to the geographical bounds of Indonesia. Therefore, no other country has been assessed in this study and this provides direction for future research where other developing countries, for instance, Thailand, Malaysia, Pakistan or China. Provided this, the research in future can be further enhanced by incorporating control variables like exchange rate, inflation, interest rate.
\end{abstract}

Keywords: Oil price, Oil price volatility, Commodity, GDP, Economic progress, Indonesia.

\section{Introduction}

One of the most important energy source that plays a vital role in the industrial sector of an economy is crude oil and by-products made from it. This is mainly considered to be important as it is used as the fuel as well as raw material in the process of production. Therefore, it is expected that the prices of oil may affects the economic conditions of the country. It is analysed from the previous studies (Aloui, Hkiri, Hammoudeh, \& Shahbaz, 2018; Pradhan, Arvin, \& Ghoshray, 2015; Sodeyfi \& Katircioglu, 2016) that the prices of oil are associated with the inflation as well as growth in the economy. As the prices of the oil accounts for the cost of production of several inputs so by the increase of oil prices, the total cost of products within a domestic market would also increase (Artami \& Hara, 2018; Qisthi, 2019). The cost of input has been increased due to the increase in prices of oil which also decrease the supply of input which in turn decreases the total output leading to decrease in economic productivity (Akhmad, Romadhoni, Karim, Tajibu, \& Syukur, 2019). Due to this reduction in the productivity, there is a great decline observed in the wages of the people as well as the unemployment also increases which leads to the high inflation in the economy.

Indonesia is a developing country and the economy of the country mainly relies over the oil as it mainly contributes in the gross domestic product of the country and it also helps in affecting the total trade balance as well as expenditure of the government. The country is also known as the net exporter of the oil and is mainly dependent over the oil as it is the main source of revenue of the country (Sha, 2017). From the year of 2005, the country has shifted its image from net exporter of oil to the importer of the oil and the contributions of oil to the income have been decreased which resulted in the production of the oil declining due to the depletion of the resources (Abdlaziz, Rahim, \& Adamu, 2016); (Roespinoedji, Roespinoedji, Siam, \& Shamsudin, 2019); (Adam, Saidi, Rahim, \& Rosnawintang, 2019). It is investigated that Indonesia contained a large reserves of the crude oil in 2015 that contributes to the production of decline by $50 \%$ along with the revenue which can be decrease when the total percentage of GDP can be measured.

There is a deficit balance of trade in the sector of oil and gas due to this deficit balance of trade. This is mainly from the increasing trend of consumption of oil. The share of oil in the primary energy mix of Indonesia was targeted to be $40 \%$ in the year of 2015 which indicated it heavy dependence over the oil (Adam et al., 2019). The consumption of oil in Indonesia has been doubled since 1990, thus due to the reduction in the production of oil as well as increasing demand for oil shows the growing deficit balance of trade in oil and gas sector. The share of oil in government expenditure of Indonesia is substantial. The subsidy of the fuel is considered as a burden over the national budget of Indonesia from the past several years. By following this scheme, the fuel products are sold based upon fixed prices that is below the price of market which is determined by the government (Hossain \& Raghavan, 2019). Therefore, an effort is made by the government of Indonesia which reduces the fossil fuel subsidies by eliminating the subsidy for several petroleum products that gradually links with the international price of oil. 
However, this results in the fluctuations in the fuel prices in Indonesia which is mainly associated with inflation leading to decline in economic growth.

The main aim of the study is to find out the impact of fluctuations of oil prices on the gross domestic product of Indonesia. The secondary objectives in order to achieve the main aim are:

- To understand the factors that cause the fluctuations in oil prices throughout the globe

- To examine whether there is an impact of fluctuations of oil prices on the gross domestic product on Indonesia or not

- To provide recommendations to relevant authorities regarding the measures to be taken during the time of high fluctuations of oil prices

The main research question that is analysed in the study is:

Do fluctuations of oil prices possess any impact on the gross domestic product of Indonesia?

\section{Literature Review}

The prices of the oil are considered as an important factor of the global economic performance. It is analysed that the increase in the prices of oil leads towards the transfer of the income from exporting as well as importing countries which leaves a great shift in trade balance of a country. In the study of Hooker (2002) an explanation is provided regarding the impact among the prices of oil as well as inflation. A model is proposed in which rate of change of oil prices and unemployment gap is discussed which includes prevailing rate of unemployment to the benchmark that is known as the natural rate of unemployment which also lagged inflation in order to predict the core PCI inflation (Belhaj, Suboyin, \& Ali, 2018); (Alam, Hairani, \& Singagerda, 2019).

In the end of 1980, the relationship among these variables was tested by using statistical tests. It was analysed that there is significant impact of oil prices on inflation in the earlier period but this is not applicable in recent periods due to market dynamics (Hossain \& Raghavan, 2019). It is also investigated that the prices of the oil have a stagflation effects over the macroeconomic indicators of a country that imports the oil. There is a great effect of the size on output growth effect and inflation level mainly relies over several factors. These factors includes the size of the shock in terms of the percentage which increases the prices of the oil and the prices that are real (Hadi, Yahya, \& Shaari, 2017; Novarinda, 2016; Tabash \& Khan, 2018). In addition to this, the persistence of the shock and the dependency of economy over the energy and oil and the last factor includes the policy response of the authorities that are fiscal and monetary.

A number of researches have shown that the economic activities can respond to the changes in oil prices asymmetrically. There is dissimilar magnitude of the effect of same change in the prices of the oil when there is a positive change as compared to when there is adverse change. It is considered as a significant findings as it has ability to capture the impact upward as well as downward in the prices of the oil (Belhaj et al., 2018). However, there is a mixed asymmetry of such empirical evidence. It is investigated that there are several positive changes in the prices of the oil that have adverse impacts over the economic activities.

There is a great impact of the changes in the oil prices over the growth in economy and inflation in the emerging countries in which most of Asian countries are included (Qisthi, 2019). The economies of the Iran and China are considered to be very sensitive over the asymmetry effects of the downward changes in the prices of oil as compared to the upward changes in the price of oil (Akhmad et al., 2019; Sha, 2017). Moreover, it is evaluated that the asymmetric impact of the change of oil price is not present due to the linear and non-linear changes in the price of oil over the economy of Malaysia and Indonesia.

There are several factors that are known as the causes of asymmetric impact including monetary policy, adjustment costs as well as product prices of petroleum things. It is investigated that the monetary policy has a major impact over the change in oil price as it has asymmetric effects over the economy and the main reasons listed behind this are the increase in inflation rate and unemployment in Indonesia. The asymmetry can take place when there are combination of the factors that keep nominal GDP constant (Abdlaziz et al., 2016).

This is mainly due to the inflation which is not expected and the disinflation that is precipitated by the monetary policy. Secondly, it is investigated that the differential input ration, coordination problems and the sectorial imbalances are considered as the factors leading adjustment costs that are more affected by the oil prices and needs more time to be adjusted (Adam et al., 2019). In Indonesia, there is a high rate of unemployment which is caused due to the rise in the prices of oil. It is mainly due to the fact that the adjustments are caused between the contraction of the sectors that depends over the energy as well as expansion of the sectors that are less dependent over the energy as it need more time to achieve (Artami \& Hara, 2018; Qisthi, 2019).

It is also analysed that the asymmetric impact of the changes in the price of the oil would be caused by the different changes in the price of the petroleum product to the changes of crude oil which is mainly due to different policies that are applicable over prices of petroleum product like subsidy of fuel (Belhaj et al., 2018). Although the phenomena of fluctuation in the price of oil is considered to be very important for countries that are emerging into the global economic scenario including Indonesia, where the economy of country relies over a strong industrial sector and economies that are emerging have shown that they rely over oil.

There is another impact of the increase in the price of the fuel which is inflation. Increase in the price of the fuel is one of the greatest cause of the inflation in developing countries like Indonesia and Malaysia. The fuel prices are increased which is also followed by the increase in the prices of the product of non-oil product in which the basic necessities and the goods for consumption are included. The price of all the economy depends over the price of the oil as it is involved in almost every aspect (Adam et al., 2019); (Tabash \& Khan, 2018). In addition to the direct impacts, there is an indirect impact that is regarding the behaviour of the workers and their response.

It is specified that the companies put all their efforts in diverting increase in the cost production by increasing the selling price of the product for the consumers. In addition to this, the workers also demand high wages for their work due to the economic disturbance in the country. The study over impact of fuel oil price over the change on macroeconomic level shows that the macro economy is mainly impacted by the prices of fuel. When the price of oil in international market was less than USD23 in the year of 2003, it increased until it reached to the peak in the year of 2008 that is USD 140 per barrel. In the year of 2009 , there was a sharp decrease observed in the prices by 
USD40 per barrel which is not for a long time (Tabash \& Khan, 2018); (Hadi et al., 2017); (Alam et al., 2019). After that the price is continuously increasing which impacts the economy of the country. Considering all the discussion presented in the context of how an economy is dependent on its commodity market and specifically oil, the following hypothesis has been constructed to evaluate later in this study.

$H_{1}$ : The oil price fluctuations significantly influence the economic progress of Indonesia

\section{Methodology}

The research is quantitative in nature as the data collect is in numeric form. The data is collected from the official statistical website on Indonesia and World Bank while data regarding the fluctuations in oil prices is collected from Bloomberg and Investing.com. A total of 10 years data is collected so the sample size of the study is 10 years. The unit root test is conducted in order to find out whether the data is stationary or not. Afterwards, autoregressive distributed lag (ARDL) analysis is conducted in order to find the impact of fluctuations of oil prices on the gross domestic product.

\subsection{Unit Root Testing}

The unit root test is conducted in order to find out whether the data is stationary or not. Afterward, autoregressive distributed lag (ARDL) analysis is conducted in order to find the impact of fluctuations of oil prices on the gross domestic product. Here it becomes important to mention that monthly data for both the time series have been collected from the year 2009 to 2018 in the context of Indonesia. With reference to the findings of Cohen (2014) the processing of a time series involves certain limitations and assumptions that are required to be followed while predicting and evaluating the one time series from the other. Therefore, it becomes important to describe how certain assumptions and criteria are essential to consider during the econometric assessment. Independent Variable: Fluctuations of Oil Prices

Dependent Variable: Gross Domestic Product

Additionally, this can also be comprehended through empirical equation as follows:

$$
F O P_{t}=\alpha+\beta_{i}\left(G D P_{t}\right)+\varepsilon
$$

In the current research, the researcher has intended to apply Augmented Dickey-Fuller and Autoregressive Distributed Lag. In this regard. Therefore, an explanation to the methods and statistical technique applied to the current research are as followed:

\subsection{Augmented Dickey-Fuller (ADF)}

In the present research, the researcher has intended to determine the impact of oil price fluctuations to the growth domestic product of Indonesia. In order to comprehend the current research phenomenon, the researcher has collected time series for oil price fluctuations and GDP for ten years. However, it has been argued through the findings of Bekhet, Matar, and Yasmin (2017), time-series data need to comply with certain assumptions. Different kinds of assumption criteria are being discussed while processing the econometric assessment. Similarly, one of the fundamental criteria is also being referred to as stationarity of time series. With regards to the findings of Chaudhuri and Ghosh (2016), one of the essential technique which is preferably utilised for evaluating the stationarity of a time series is considered as ADF technique. Further, it has also been stated that the ADF technique forms the basis with the supposition of the null hypothesis of a time series that entails unit roots. In this aspect, the acceptance and rejection of a null hypothesis determine whether or not the time series entails unit-roots. Moreover, once it is confirmed that the time series possess unit-roots, then, in this case, it can be stated that the data is non-stationary. In contrast, when it is determined that the time series does not entail unit-roots, then the time series can be claimed as stationary. The mathematic model reflecting ADF'a approach has also been presented below:

$$
\Delta \mathrm{a}_{t}=\lambda_{0}+\lambda_{1} \mathrm{t}+\lambda_{2} \mathrm{a}_{t-1}+\sum_{i=1}^{n} n i 1 \Delta \mathrm{a}_{t-1}+¥
$$

In the aforementioned equation, $\Delta$ can defined as the difference operator. Meanwhile, $¥$ can be described as the random error of stationary. In addition, $\mathrm{a}_{t}$ reflects non-stationary series.

\subsection{Autoregressive Distributed Lag (ARDL)}

One of the most widely used statistical analysis techniques for determining long-term association during an econometric assessment is concerned with the Autoregressive Distributed Lag technique. Concerning the findings of Nkoro and Uko (2016) an ARDL approach is preferably used for determining the long-term association between the two quantifiable variables. The technique forms the basis with the iterative approach where the marginal log of time series is also maximised. The standard log-linear function has also been presented as followed:

$$
G_{t}=\beta+\alpha \mathrm{ER}_{t}++¥_{t}
$$

In the equation above, $G_{t}$ represents the $\log$ of GDP. $¥_{t}$ denotes error terms while $\alpha$ is parameter estimate. The mathematical model for the developed ARDL is also presented as followed:

$\Delta G_{t}=\beta 1+\sum_{i=1}^{m 1} \theta_{1 i} \Delta G_{t-i}+\gamma_{1} G_{t-1}+\gamma_{2} F O P_{t-1}+¥_{t}$

Additionally, the long term and short-term dynamics for the concerned ARDL has also been presented through the following mathematical models:

$$
\begin{gathered}
\Delta G_{t}=\beta 2+\sum_{i=1}^{m 2} \alpha_{2 i} \Delta G_{t-i}+\sum_{j=0}^{n 2} \alpha_{2 j} \Delta F O P_{t-j}+¥_{2 t} \\
\Delta G_{t}=\beta 3+\sum_{i=1}^{m 3} G_{3 i} \Delta Y_{t-i}+\sum_{j=0}^{n 3} \alpha_{3 j} \Delta F O P_{t-j}+\phi \varepsilon_{t-1}+¥ ¥_{3 t}
\end{gathered}
$$

Here $\phi$ denotes a statistically significant coefficient which is corrected for error. 


\section{Results}

For the purpose of evaluating the data accumulated in accordance with the proposed method, the results have been presented, discussed and analysed in this section. Therefore, this sections discusses the descriptive statistics with respect to the variables of the research, evaluation of unit roots in the data because the data is time-series and assessment of the association using ARDL approach.

\subsection{Descriptive Statistics}

This specific section includes the assessment of the average oil fluctuations during the 10 years period along with the mean value of the economic progress of the Indonesian economy. In addition, the assessment also includes minimum and maximum values. On the other hand, the deviation has also been calculated using standard deviation. For the purpose of evaluating the normality of the series of each variable, Jarque Bera has also been computed and evaluated. The results depicted in Table 1 are asserting that the average GDP value is 93.494 points during the span of 10 years whereas, average oil price change is computed to be $0.5 \%$. In addition, the maximum value of GDP is computed to be 118.251 whilst the minimum value is computed to be 70.348 points. In furtherance, the maximum value of oil price fluctuation or volatility is computed to be $20.51 \%$ whilst the minimum value is computed to be $22.88 \%$ points. In terms of standard deviation, it has been found that the deviation in GDP index is 6.62 whilst the deviation in oil price fluctuations is calculated to be $7.82 \%$.

In certain statistical and analytical techniques, the data is assumed to be normally distributed (Cohen, 2014). In terms of the Jarque Bera statistics, GDP has statistics equal to 6.6 (p-value $=0.04$ ) while the other variable of the study has 5.53 computed statistics with $\mathrm{p}$-value $=0.06$. In this concern, it can be inferred from the statistics that at $1 \%$ level of significance, both the data series can be regarded as normally or approximately normally distributed. The results have been presented in Table 1.

Table-1. Descriptive statistics of the research variables.

\begin{tabular}{c|c|c}
\hline & GDP (Index) & Oil Price Fluctuation \\
\hline Mean & 93.494 & $0.50 \%$ \\
\hline Maximum & 118.251 & $20.51 \%$ \\
\hline Minimum & 70.348 & $-22.88 \%$ \\
\hline Std. Dev. & 13.987 & $7.82 \%$ \\
\hline Jarque Bera & 6.62 & 5.53 \\
\hline Probability & 0.04 & 0.06 \\
\hline
\end{tabular}

\subsection{ADF Testing to Evaluate Unit Root}

The analysis of the presence of unit root has been conducted using ADF test as discussed in the methodology section as well. The null hypothesis assumes the data to have non-stationary characteristics. In this concern, both variables of the study have been evaluated using E-Views and the results have been presented in Table 2. In accordance with the results, GDP's t-statistic is computed to be 0.108 with the probability value of 0.997. This implies that the p-value is greater than all the assumed thresholds, for instance $10 \%, 5 \%$ or $1 \%$. Therefore, GDP is found have unit root. On the contrary, the results in Table 2 are also depicting oil price fluctuations and it has been found that the $\mathrm{p}$-value is computed to be -8.268 with a $\mathrm{p}$ - value of 0.000 ( $\mathrm{p}$-value $<0.05)$. In this aspect, it can be inferred that this data series is stationary and does not contain any unit root because the null hypothesis is negated. Considering the mixed nature of data series in this study, the later methodology has been decided accordingly.

Table-2. ADF approach to unit root testing.

\begin{tabular}{c|c|c}
\hline ADF Testing & t-statistics & Probability Value \\
\hline GDP & 0.108 & 0.997 \\
\hline Oil Price Fluctuations & $-8.268^{* * *}$ & 0.000 \\
\hline Note: *** is indicating significance of the results at $\alpha=1 \%$.
\end{tabular}

Note: *** is indicating significance of the results at $\alpha=1 \%$.

\subsection{Autoregressive Distributed Lag Model}

Since it has been found that the nature of data series in this study is mixed where one has unit root whilst the other is stationary, therefore, the chosen model for the assessment is ARDL. The results presented in Table 3 firstly indicates the optimal lag order which has been chosen automatically by E-Views. To further strengthen the assessment, the errors are fixed using HAC errors. Also, the initial assessment also included evaluation of trend which was found to be insignificant. Concerning the selection of the optimal model, it has been found that GDP is significantly and positively dependent on its first lag $(B=0.852$ with $p-$ value of $0.000<0.01)$. Therefore, the GDP in future can be predicted with the lagged value of GDP index itself. On the contrary, it can be seen that the dependency of GDP index on its second lag is not found to be significant $(\mathrm{B}=0.000$ with $\mathrm{p}-$ value of $0.982>0.1)$. Hence, with the second lag, the GDP index can be insignificantly predicted. However, on the basis of third and fourth lags of the GDP, the values are found to be significant $(B=1.010$ with $p$ - value of $0.000<0.01)$ and $(B=-$ 0.862 with $\mathrm{p}-$ value of $0.000<0.01)$ respectively. Consequently, the short run association of GDP index of Indonesia with the lagged values is found to be significant.

Besides, the primary question of the study was to assess the association and effect of oil price fluctuations. At level, it has been found that the effect is computed to be statistically insignificant as depicted in Table 3. The inference has been drawn because the $\mathrm{p}$-value is greater than the set thresholds $(\mathrm{B}=-0.028$ with $\mathrm{p}$ - value of 0.553 $>0.1)$. However, if the lagged value of the oil price fluctuations is evaluated, it can be concluded that GDP is dependent on oil price fluctuations in the case of Indonesia only in the short run. This assertion has been drawn on the basis of $p$-value $(B=0.095$ with $p-$ value of $0.000<0.01)$. In can be deduced that the effect is both positive and significant which implies that boost in the fluctuations in the oil prices of Indonesia as a commodity would result in boost in the GDP index in the short run. The results have been depicted in the following Table. In addition, the 
overall model is found to be statistically significant because the p-values of the Fisher's statistics is lower than $5 \%$. The standard errors of the coefficients have also lower values implying lower chance of error.

Table-3. ARDL Model of the Research

\begin{tabular}{|c|c|c|c|c|}
\hline \multicolumn{5}{|c|}{ Automatic Optimal Lag Order Selection: ARDL $(4,1)$} \\
\hline Variable & Coefficient & Std. Error & t-Statistic & Prob.* \\
\hline $\operatorname{GDP}(-1)$ & $0.852 * * *$ & 0.045 & 18.850 & 0.000 \\
\hline $\operatorname{GDP}(-2)$ & 0.000 & 0.007 & -0.022 & 0.982 \\
\hline $\operatorname{GDP}(-3)$ & $1.010 * * *$ & 0.007 & 145.144 & 0.000 \\
\hline GDP $(-4)$ & $-0.862 * * *$ & 0.046 & -18.892 & 0.000 \\
\hline Oil Price Fluctuation & -0.028 & 0.046 & -0.595 & 0.553 \\
\hline Oil Price Fluctuation $(-1)$ & $0.095 * *$ & 0.047 & 2.030 & 0.045 \\
\hline $\mathrm{C}$ & $0.098 * * *$ & 0.037 & 2.671 & 0.009 \\
\hline R-squared & $99.999 \%$ & & F-statistic & 2540351.000 \\
\hline Adjusted R-squared & $99.999 \%$ & & Prob (F-statistic) & 0.000 \\
\hline
\end{tabular}

\subsection{Hypotheses Assessment Summary}

The primary evaluation of the study revolved around the effect of oil price fluctuations on the GDP index. It was found that oil price volatility affected the economic progress of Indonesia positively in the short-run. It was also evaluated that GDP is significantly dependent on its lagged values. Therefore, on the basis of the statistical evidence, the hypothesis proposed initially has been accepted.

\section{Discussion}

In the past, several researches have already analysed the association between oil prices and the economy. However, since these variables are time-variant, therefore, it is necessary to evaluate the association over the period of time to further assess the underlying factors and the potential changes for predicting the future. In this concern, this research has found that in the context of Indonesia, the association and effect of oil price on the GDP index or the economy is computed to be significant in the long-run. The findings of the study in this case is consistent with various studies. It has been investigated by Hadi et al. (2017); Tabash and Khan (2018) and Novarinda (2016) that output growth effect and inflation levels are influenced by several factors. These factors includes the size of the shock in terms of the percentage which increases the prices of the oil. Therefore, the findings are coherent with researches conducted on other countries as well depicting the similarity in the dynamics of the countries. The research carried out by Belhaj et al. (2018) stated that the economic activities can respond to the alterations in oil prices asymmetrically. In the case of the results of this study, it has been found that the effect in the short run is positive of the oil fluctuations on the GDP index and this implies that the nature is asymmetric. Considering the relevance of the study, this research has various practical implications for the government and the other authorities associated with the commodity market and especially oil market to devise such policies in Indonesia that can foster the growth of commodity market and economy as a whole. In fine, the findings of the study are also supported by various researches, however, it can be enhanced further on the basis of key areas highlighted in the later sections of the paper.

\section{Conclusion}

Conclusively, GDP index or economic progress of Indonesia is found to be significantly affected by the oil prices and its fluctuations. Therefore, the underlying mechanisms that could control or keep the flow in balance hold significant importance. The government needs to devise policies for oil market and this proposition has been given on the basis of findings of this study. The authorities are responsible for nurturing the environment in Indonesia leading to economic growth. Precisely, the government is required to create a mechanism for commodity market to gain optimality in the production, imports and exports of oil and to curb the issues prevailing in Indonesia, for instance unemployment.

\section{Limitations of the Study and Future Directions}

The research underpinned the case of Indonesia for evaluation and since this scope has been defined, it further entails to the inference that this research is limited to the geographical bounds of Indonesia. Therefore, no other country has been assessed in this study and this provides direction for future research where other developing countries, for instance, Thailand, Malaysia, Pakistan or China. In furtherance, GDP has been considered as a metric for economic progress, and in future, other metrics, for instance, GNP can be considered. Provided this, the research in future can be further enhanced by incorporating control variables like exchange rate, inflation, interest rate. In addition, comparative analysis can also be conducted in future between the countries.

\section{References}

Abdlaziz, R. A., Rahim, K. A., \& Adamu, P. (2016). Oil and food prices co-integration nexus for Indonesia: A non-linear autoregressive distributed lag analysis. International Journal of Energy Economics and Policy, 6(1), 82-87.

Adam, P., Saidi, L. O., Rahim, M., \& Rosnawintang, R. (2019). The effect of crude oil prices on economic growth in south east sulawesi, Indonesia: An application of autoregressive distributed lag model. International Journal of Energy Economics and Policy, 9(2), 194-198.

Akhmad, A., Romadhoni, B., Karim, K., Tajibu, M. J., \& Syukur, M. (2019). The impact of fuel oil price fluctuations on Indonesia's macro economic condition. International Journal of Energy Economics and Policy, 9(2), 277-282.

Alam, I. A., Hairani, H., \& Singagerda, F. S. (2019). Price determination model of world vegetable and petroleum. International Journal of Energy Economics and Policy, 9(5), 157-177. Available at: https://doi.org/10.32479/ijeep.7916.

Aloui, C., Hkiri, B., Hammoudeh, S., \& Shahbaz, M. (2018). A multiple and partial wavelet analysis of the oil price, inflation, exchange rate, and economic growth nexus in Saudi Arabia. Emerging Markets Finance and Trade, 54(4), 935-956. Available at: https://doi.org/10.1080/1540496x.2017.1423469. 
Artami, R. J., \& Hara, Y. (2018). The asymmetric effects of oil price changes on the economic activities in Indonesia. Significant: Journal of Economics, 7(1), 59-76. Available at: https://doi.org/10.15408/sjie.v7i1.6052.

Bekhet, H. A., Matar, A., \& Yasmin, T. (2017). CO2 emissions, energy consumption, economic growth, and financial development in GCC countries: Dynamic simultaneous equation models. Renewable and Sustainable Energy Reviews, 70, 117-132.

Belhaj, H. A., Suboyin, A., \& Ali, S. A. (2018). Assessment of petroleum sensitive countries economic reforms in reaction to fluctuating oil prices. Paper presented at the In SPE Annual Technical Conference and Exhibition. Society of Petroleum Engineers.

Chaudhuri, T. D., \& Ghosh, I. (2016). Artificial neural network and time series modeling based approach to forecasting the exchange rate in a multivariate framework. arXiv preprint arXiv:1607.02093.

Cohen, M. X. (2014). Analyzing neural time series data: Theory and practice: MIT Press.

Hadi, A. R. A., Yahya, M. H., \& Shaari, A. H. (2017). The effect of oil price fluctuations on the Malaysian and Indonesian stock markets. Asian Journal of Business and Accounting, 2(1\&2), 69-91.

Hooker, M. A. (2002). Are oil shocks inflationary? Asymmetric and nonlinear specifications versus changes in regime. Journal of Money, Credit and Banking, 34(2), 540-561. Available at: https://doi.org/10.1353/mcb.2002.0041.

Hossain, A. A., \& Raghavan, M. (2019). Drivers of inflation and inflation volatility and their effects on macroeconomic fluctuations in Indonesia and Thailand. Available at SSRN 3450965.

Nkoro, E., \& Uko, A. K. (2016). Autoregressive distributed lag (ARDL) cointegration technique: Application and interpretation. Journal of Statistical and Econometric Methods, 5(4), 63-91.

Novarinda, L. (2016). Analysis the impact of world oil price fluctuations on Indonesia economic. Paper presented at the In International Conference on Education For Economics.

Pradhan, R. P., Arvin, M. B., \& Ghoshray, A. (2015). The dynamics of economic growth, oil prices, stock market depth, and other macroeconomic variables: Evidence from the G-20 countries. International Review of Financial Analysis, 39, 84-95. Available at: https://doi.org/10.1016/j.irfa.2015.03.006.

Qisthi, S. (2019). The impact of world crude oil price fluctuation on Indonesia's macroeconomy.

Roespinoedji, D., Roespinoedji, R., Siam, M. R., \& Shamsudin, M. F. (2019). An empirical study on short term and long-term consequences of crude oil on economic wellbeing of indonesia by applying autoregressive distributed lag model. International Journal of Energy Economics and Policy, 9(5), 474-480. Available at: https://doi.org/10.32479/ijeep.8311.

Sha, T. L. (2017). Effects of price earnings ratio, earnings per share, book to market ratio and gross domestic product on stock prices of property and real estate companies in indonesia stock exchange. Journal of Economic ङ Management Perspectives, 11 (1), $1743-1754$.

Sodeyfi, S., \& Katircioglu, S. (2016). Interactions between business conditions, economic growth and crude oil prices. Economic Research, 29(1), 980-990. Available at: https://doi.org/10.1080/1331677x.2016.1235504.

Tabash, M. I., \& Khan, S. H. (2018). The impact of oil price volatility, gross domestic product, foreign direct investment on Islamic banking investments: An empirical evidence of the United Arab Emirates. International Journal of Energy Economics and Policy, 8(5), 306-312.

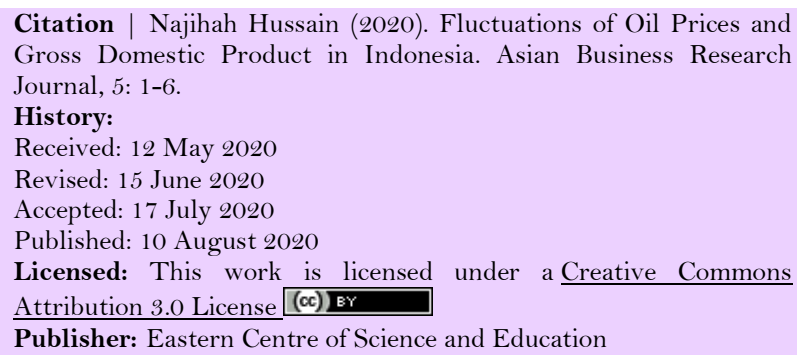

Publisher: Eastern Centre of Science and Education

Eastern Centre of Science and Education is not responsible or answerable for any loss, damage or liability, etc. caused in relation to/arising out of the use of the content. Any queries should be directed to the corresponding author of the article.

Funding: This study received no specific financial support.

Competing Interests: The author declares that there are no conflicts of interests regarding the publication of this paper.

Transparency: The author confirms that the manuscript is an honest, accurate, and transparent account of the study was reported; that no vital features of the study have been omitted; and that any discrepancies from the study as planned have been explained.

Ethical: This study follows all ethical practices during writing. 